\title{
ANOREXIA MENTAL E FEMINILIDADE
}

Simone Pencak e Angélica Bastos

Simone Pencak Psicanalista, médica psiquiatra do Hospital Universitário Pedro Ernesto (Núcleo de Estudos da Saúde do Adolescente), pós-doutoranda no Programa de Pós-graduação em Teoria Psicanalítica da UFRJ.

Angélica Bastos Psicanalista, professora associada no Programa de Pós-graduação em Teoria Psicanalítica, Bolsista de Produtividade em Pesquisa do CNPq.
RESUMO: Pretende-se discutir a anorexia e sua incidência preponderante em jovens mulheres, extraindo da teorização da experiência indicações para a direção do tratamento psicanalítico. Discute-se a anorexia como sintoma contemporâneo e examina-se a hipótese de uma estratégia de paridade entre os sexos. A resposta anoréxica é articulada à problemática da sexuação no ensino de Jacques Lacan, sendo tal resposta circunscrita ao impasse relativo à inexistência do universal das mulheres. Com um fragmento de caso, interroga-se a manobra de instituir uma exceção no lado mulher da partilha sexual e aponta-se a função da angústia nesta clínica.

Palavras-chave: Anorexia, feminilidade, sexuação, psicanálise, Jacques Lacan.

ABSTRACT: Mental anorexia and femininity. This paper aims at discussing anorexia and its predominant incidence among young women, drawing out some indications for psychoanalytical treatment from the experience theorization. Anorexia as a contemporary symptom is discussed and the hypothesis of a parity strategy between the genders is examined. The anorectic response is articulated to the problematic of sexuation in Jacques Lacan's teaching. Such response is circumscribed in the impasse related to the nonexistence of the women's universality. Based on a case fragment, an interrogation is made upon the maneuver to establish an exception on the woman's side of the gender division and the anguish function in this clinic is indicated.

Keywords: Anorexia, feminity, sexuation, psychoanalysis, Jacques Lacan.

\section{INTRODUÇÃO}

A anorexia mental constitui um sintoma que interroga o psicanalista em sua prática, para além de qualquer afirmação de que estejamos assistindo na atualidade a um aumento no número de pacientes anoréxicas, tanto nos consultórios quanto nas instituições de atenção à saúde.

As descrições clínicas da anorexia remontam a 1689, apesar de os termos 'anorexia nervosa' ou 'anorexia histérica' só terem 
aparecido na literatura especializada por volta do ano de 1870, com os trabalhos de William Gull e Charles Lasègue (BIDAUD, 1998, p.15-16). Cabe apontar que as descrições deste último são bastante precisas, não só do ponto de vista dos fenômenos, mas também quanto à apreensão de uma dinâmica psíquica particular em jogo na condição desses doentes. Daí, Lasègue referir-se a um "otimismo inexpugnável”, a um “consentimento patológico” e ao surpreendente fato de que a paciente "não suspira pela cura, mas se compraz na sua condição, apesar de todas as restrições que esta lhe suscita” (LASÈGUE apud BIDAUD, 1998, p.17).

Mais recentemente, observa-se que à descrição psiquiátrica clássica do quadro patológico - incluindo em geral a recusa alimentar derivada de fatores mentais ou "nervosos", emagrecimento importante e amenorreia —, acrescentou-se o dado fenomênico de um transtorno da imagem corporal, sendo este último promovido ao estatuto de fator patognomônico, quando não etiológico, da doença. A partir daí, tem se tentado inferir que a anorexia mental seria um sintoma contemporâneo vinculado ao ideal de corpo magro vigente na sociedade atual. Veremos mais adiante os limites e contradições dessa concepção.

Quanto ao campo psicanalítico, notamos que as indicações freudianas são raras e esparsas. Encontra-se o sintoma anoréxico das jovens meninas ora como "uma forma de melancolia nos sujeitos de sexualidade não inteiramente desenvolvida” (FREUD, 1895/1986, p.240) — sendo a perda de apetite relacionada à perda de libido - , ora como neurose que ocorre "nas meninas na época da puberdade ou pouco depois, e que exprime a aversão à sexualidade por meio da anorexia", devendo "ser vinculada com a fase oral da vida sexual" (FREUD, 1918 [1914]/1986, p.97). Perda de libido de um lado, aversão à sexualidade do outro, a perspectiva freudiana oscila entre uma aproximação da anorexia com a melancolia e sua inclusão no campo da histeria.

Não deve passar despercebido que o sintoma anoréxico, tanto nas descrições da psiquiatria clássica quanto na obra freudiana, aparece como um sintoma feminino por excelência, um sintoma que atinge particularmente mulheres, e em especial mulheres jovens, fato comprovado por diversas pesquisas médicas. Cabe nesse momento a pergunta que nos parece fundamental: qual será a razão dessa esmagadora incidência em mulheres jovens?

As contribuições lacanianas ao tema dizem respeito à dialética da demanda e do desejo. Seguindo esta orientação, adotamos a designação 'anorexia mental', que põe em relevo a dimensão da recusa ao objeto da necessidade e ao Outro da demanda. Se "é a criança alimentada com mais amor que recusa o alimento e usa sua recusa como um desejo (anorexia mental)” (LACAN, 1958/1998, p.634), é porque a recusa do alimento visa fazer surgir o que está para além da demanda alimentar, ou seja, o desejo do Outro. E também, como escreve Lacan em forma de pergunta, “a criança, ao se recusar a satisfazer a demanda da mãe, não exige 
que a mãe tenha um desejo fora dela, porquanto essa é a via que lhe falta rumo ao desejo"? (LACAN, 1958/1998, p.634)

Além disso, verifica-se um empenho no ensino lacaniano em vincular a anorexia mental a um "comer nada”, diferenciado radicalmente de "uma negação da atividade”, de um "não comer”. "Graças a este nada, ela (a criança) faz a mãe depender dela" (LACAN, 1956-1957/1995, p.189), em uma manobra que inverte a relação inicial de dependência do sujeito em relação ao Outro materno, a recusa alimentar coloca em jogo o "nada” como objeto separador.

Recalcati propõe situar "uma clínica diferencial da anorexia" por meio da distinção de dois estatutos do "nada” e, assim, "esboçar uma clínica diferencial do nada”. Um primeiro comer "nada” estaria ligado à histeria, portanto à neurose, em que a recusa alimentar vale como suporte e escudo do desejo, em oposição à demanda sufocante do Outro, visando fazer surgir o signo do amor no Outro. Trata-se, nesse primeiro caso, de uma operação de "separação contra alienação", ou seja, a anoréxica buscaria desvincular-se da operação subjetiva estrutural da alienação ao campo da linguagem, ao campo do Outro, através de uma "pseudo-separação" (RECALCATI, 2001, p.28, 29; e também: SILVA \& BASTOS, 2006, p.105).

O segundo "nada”, associado por Recalcati ao princípio de nirvana freudiano, à pulsão de morte, seria mais uma anulação do desejo, uma "redução do desejo a nada”, e estaria então ligado às "formas graves de anorexia”, "estruturalmente psicóticas” (RECALCATI, 2001, p.26-36).

Nesse ponto, caberia introduzir algumas perguntas relativas, de início, às próprias formulações de Lacan sobre a anorexia. As proposições lacanianas mencionadas referem-se à anorexia da criança em sua relação com a demanda materna. Haveria uma continuidade lógica entre a anorexia infantil e a anorexia que aparece na puberdade, especialmente em meninas? Seria a anorexia da puberdade uma reatualização da anorexia infantil? A experiência clínica parece contradizer de certo modo essa hipótese, no sentido em que, em grande parte dos casos nos quais o sintoma aparece na puberdade, observamos que não há a contrapartida de um período significativo de anorexia infantil na história do sujeito.

Por outro lado, quanto às contribuições de Recalcati, poderíamos avançar as seguintes interrogações: em primeiro lugar, não será uma "pseudo-separação" o que se opera no sintoma neurótico como tal, e não apenas no sintoma anoréxico? Parece-nos que é exatamente sobre essa “pseudo-separação” promovida pelo neurótico que irá incidir a intervenção analítica. Em segundo, o que diferencia “a nirvanização do sujeito”, correlativa ao segundo "nada” referido pelo autor — "pura expressão da pulsão de morte” (RECALCATI, 2001, p.34) —, do negativismo do sujeito melancólico? 
A expressão "meninas jovens" que encontramos tanto nas descrições psiquiátricas clássicas da anorexia quanto na obra freudiana nos encaminha para um exame do sintoma anoréxico em sua articulação com a questão da feminilidade.

Nossa proposta, neste trabalho, é abordar a anorexia mental como uma resposta particular de alguns sujeitos aos problemas colocados pelo desejo e pelo gozo femininos. Partimos da experiência clínica em que se verifica a incidência do sintoma em mulheres, sobretudo na fase da puberdade. Pretendemos também avançar uma discussão a respeito da contemporaneidade do sintoma anoréxico, e sobre as particularidades da direção do tratamento.

\section{ANOREXIA MENTAL, SEXUAÇÃO E NOMEAÇÃO}

Tomaremos inicialmente como apoio o quadro da sexuação na teoria de Lacan, estabelecido em seu Seminário a partir dos anos 1970, em que se trata de postular duas inscrições subjetivas na divisão dos sexos através de fórmulas lógicas (LACAN, 1972-1973/1985, p.105).

Confrontamo-nos aí com a sequência do empreendimento lacaniano de matematização dos conceitos freudianos, que havia se iniciado bem mais cedo, podendo ser apontado já na formulação da metáfora paterna, nos anos 50, considerada como um novo modo de escrever o complexo de Édipo freudiano (LACAN, 1957-1958/1998, p.563).

No início da década de 70, Lacan empenha-se em propor — por meio de uma utilização subversiva das lógicas: matemática, modal e aristotélica — dois modos de subjetivação para o desejo e o gozo sexuais, dividindo os seres falantes em dois lados: a parte homem e a parte mulher.

Em numerosas ocasiões, Freud já havia revelado o embaraço que a nãoinscrição da diferença sexual no inconsciente causa na teoria psicanalítica. $\mathrm{Na}$ medida que só há um significante, o falo, para designar ambos os sexos no inconsciente, deparamo-nos com um impasse - conhecido na obra freudiana pelo nome de "rochedo da castração" — que indica que os termos 'passivo', como equivalente da feminilidade, e 'ativo', como correlato da masculinidade, deixam muitos problemas a serem resolvidos, conforme o próprio Freud (1931/1986) reconhece.

A esse respeito, diz Lacan:

“consideremos apenas os termos ativo e passivo (...) que dominam tudo o que foi cogitado sobre a relação da forma com a matéria (...). É visível, tangível que esses enunciados só se baseiam numa fantasia com a qual eles tentaram suprir o que de certa maneira não se pode dizer, isto é, a relação sexual." (LACAN, 1972-1973/1985, p.110) 
Como, então, abordar o que "não cessa de não se escrever” no inconsciente, ou seja, a relação sexual (LACAN, 1972-1973/1985, p.127)? Lacan formula o quadro da sexuação como tentativa de tratar esse impossível por uma via lógica:

"Para desenvolver as fórmulas da sexuação, para fazer possível que seja possível escrever 'não há relação sexual', Lacan apela para a lógica matemática. Aparecem, assim, proposições universais e existenciais - afirmadas ou negadas e próprias desta lógica - junto a conceitos de outro ramo da lógica, a chamada modal, tais como impossível, necessário, possível e contingente. A superposição destes conceitos tem sentido em termos da psicanálise, mas não aparece, em uma primeira aproximação, suficientemente clara do ponto de vista lógico. Por outra parte, seu manifesto está em desacordo com a lógica de Aristóteles, a respeito de que duas negações de um universal não asseguram a existência (...)” (ELMER, 1993, p.35)

Do lado esquerdo do quadro, a parte homem dos seres falantes, encontramos uma exceção que se escreve: “existe um x que diz não à castração”. Esta exceção funda - segundo Lacan — uma universalidade: "todo x está submetido à castração”. Isto é o que se lê nas duas primeiras linhas do lado esquerdo do quadro, havendo uma nodulação entre o necessário (a exceção que funda o universal) e o possível. Dito de outro modo, através da existência de Um que escapa à castração, o pai freudiano da horda primeva, pode-se postular que "todo $x$ " se submete à castração para ter acesso ao gozo sexual (LACAN, 1972-1973/1985, p.107). É importante notar que a passagem do necessário ao possível se faz através de uma contradição - subvertendo, portanto, a lógica dos quantificadores pois seria de esperar que, se há Um que nega o atributo universal, não haveria universalidade possível desse lado.

Do lado direito do quadro, o lado mulher dos seres falantes, não existe Um que faça exceção ao conjunto; portanto, não há universalidade desse lado - a universalidade da função fálica, da castração, só pode ser postulada a partir de um termo que valha como exceção - , o que Lacan vai escrever: "não-todo x" se submete à castração (LACAN, 1972-1973/1985, p.107). A consequência disto é que não há constituição possível de um universal feminino, ou seja, o conjunto das mulheres não tem uma borda, um limite — é a exceção que constitui essa borda do lado homem — - estamos então diante de um conjunto infinito. A subversão da lógica clássica se repete aqui, na medida que, quando se escreve “não todo x está na função fálica”, esperaríamos que se deduzisse daí: “existe ao menos um x que não está submetido à castração”. Lacan indica, entretanto, que a existência no lado mulher permanece indeterminada, já que não há função unificante do lado da existência, não há "A mulher” (a, artigo definido) (LACAN, 1972-1973/1985, p.98). Universalidade impossível enodada a uma existência 
contingente, eis o que se escreve desse lado do quadro da sexuação, aonde vem inscrever-se a parte mulher dos seres falantes.

O ponto fundamental a ser destacado nessa construção teórica lacaniana é a possibilidade de escrita da diferença sexual através de um quadro de fórmulas lógicas em que se articulam gozo sexual e castração, tendo como suporte a função fálica $\left(\Phi_{\mathrm{x}}\right)$. Ao mesmo tempo, Lacan avança uma “função inédita”, a do "não-todo", indicando que "quando um ser falante qualquer se alinha sob a bandeira das mulheres, isto se dá a partir de que ele se funda por ser nãotodo a se situar na função fálica. (...) Não há A mulher, artigo definido para definir o universal (...), pois (...) por sua essência ela não é toda” (LACAN, 1972-1973/1985, p.98).

Como poderíamos entender essa função do "não-todo" e quais as suas consequências para a abordagem do gozo feminino? O fato de que a parte mulher dos seres falantes seja definida como "não-toda” implica que ela tem "em relação ao que designa de gozo a função fálica um gozo suplementar"; no entanto "não é porque ela é não-toda na função fálica que ela deixe de estar nela de todo" (LACAN, 1972-1973/1985, p.99-100). Dito de outro modo:

“a essência da mulher não é a castração, é a partir do real que ela se relaciona à função fálica, real que não poderia ser simbolizado pelo significante fálico. Ela escapa, assim, em parte à castração e vai buscar alhures seu gozo suplementar. A função fálica suporta, então, as quatro fórmulas proposicionais da sexuação, com essa escolha pela parte mulher dos seres falantes de estar ou não na função fálica." (CACCIALI, 2005b)

As fórmulas da sexuação estabelecem dois modos de acesso ao desejo e ao gozo sexuais pela mediação da função fálica. Estes modos contrariam a assertiva freudiana de que "a anatomia é o destino", já que o sujeito escolhe inscrever-se do lado homem ou mulher não apenas por suas características anatômicas. Na leitura que Lacan faz dessa frase (LACAN, 1962-1963/2005, p.259), destaca-se o sentido etimológico da anatomia, a função de corte que, separando o sujeito de uma parte perdida de si, abre-lhe o acesso à via do desejo. A anatomia, o corte, é o destino, mas resta saber qual. O sujeito não deseja independentemente de sua condição sexuada. O destino de homem ou mulher depende da posição do sujeito em relação à divisão dos sexos, vale dizer, sua inscrição no lado homem ou no lado mulher. É importante indicar que se mantém aí a diferença entre os sexos — na contramão de qualquer ideologia igualitária — , e também que cada lado do quadro tem no seu andar inferior vetores que atravessam de um lado a outro, implicando que o lado homem só pode ser formulado na sua relação lógica com o lado mulher e vice-versa. 
Sobretudo, não deve escapar à nossa atenção que o uso do termo 'sexuação' em lugar de 'sexualidade' visa diferenciar, de um lado, uma ação que implica inscrever o sujeito em uma escolha sexual, e, de outro, a mera vivência de algo que seria a natureza do sexo. A sexuação designa uma operação de inserção subjetiva em um lado da partilha sexual, operação cuja convocação feita ao sujeito explicita a ausência de identidade sexual a priori para os falantes.

Depois de introduzir brevemente alguns aspectos sobre o quadro lacaniano da sexuação, retornemos à questão do sintoma anoréxico e adiantemos que J.-L. Cacciali propõe que a anorexia é "uma tentativa de estabelecer uma simetria entre os dois modos de subjetivação do desejo (homem e mulher) e que nós poderíamos considerá-la como uma resposta ao desejo do Outro social, resposta a esta questão no campo da cultura, cada um com seu desejo mas sob um modo paritário" (CACCIALI, 2005b).

Nessa hipótese, seguindo as formulações de Cacciali, a manobra anoréxica institui um acesso ao falicismo por meio de uma relação privilegiada com o falo materno, e não paterno. A mãe primordial — elevada ao patamar de grande nutridora, de detentora do objeto falo a ser transmitido à filha por doação oral - constituiria a exceção ao conjunto das mulheres castradas. Lembremos que o lado mulher no quadro da sexuação não inclui a exceção que permitiria postular o universal. Portanto, a anoréxica, por meio de sua recusa alimentar, sacrifica-se para instituir uma universalidade do conjunto das mulheres por meio da imago da mãe onipotente. Se a histérica busca “bancar o homem”, como diz Lacan (LACAN, 1972-1973/1985, p.114), a anoréxica tentaria estabelecer um universal das mulheres fazendo existir uma que o contradiga (CACCIALI, 2005b).

Ao universal dos homens corresponderia um universal das mulheres, engendrado pela lógica do sintoma anoréxico. À reivindicação de direitos iguais para os sexos, a anoréxica responde com o estabelecimento de um conjunto das mulheres em paridade com o conjunto dos homens: ambos fundados por uma exceção que lhes constitui uma borda.

Tratar-se-ia, então, de um acesso ao falicismo pela via materna, e não paterna, que permite evitar ou contornar a castração. Daí, as consequências clínicas do contraste entre um emagrecimento extremo e a frequente ausência de queixa do sujeito, o que levou alguns autores a aproximar a anorexia do mecanismo da perversão. A denominação 'perversão fria' e a aproximação com uma organização do tipo psicótico, porém não delirante (KESTEMBERG \& DECOBERT, 1972, p.190), influenciou os trabalhos de diversos pesquisadores sobre o tema no campo psicanalítico. Desse conjunto de hipóteses privilegiaremos não a ideia do falo materno a ser transmitido à menina por doação oral, mas a da tentativa de instituir a exceção para fazer existir o todo, tarefa lógica e estruturalmente impossível. Essa manobra no plano da sexuação encontra ressonância no que 
Freud (1916/1986) nos diz sobre uma tendência a que as mulheres são suscetíveis: reivindicar um lugar imaginário privilegiado e narcísico de exceção, como compensação ao dano da castração.

Deixamos aqui apenas indicada a questão, que permeia vários dos trabalhos já mencionados antes, sobre a relação da anorexia com as estruturas clínicas freudianas: psicose, neurose e perversão. Cabe salientar que não há uma posição unânime sobre o assunto, mesmo entre os autores lacanianos. Voltaremos a tratar disto mais adiante.

Quanto ao aparecimento do sintoma anoréxico na puberdade, este provavelmente encontra-se ligado às dificuldades que a menina enfrenta no processo de "tornar-se mulher”, na ausência de um traço de pertinência que garantiria sua feminilidade. "Atualmente o discurso social valoriza a magreza como traço de pertinência que valeria como universal do conjunto das mulheres. A magreza pode assim valer como uma castração, mas uma castração imaginária, sempre a ser revalidada" (CACCIALI, 2005b). A insuficiência dessa castração imaginária encarnada no corpo magro se revela no chamado 'transtorno da imagem corporal': nunca se é suficientemente magro, há sempre algo mais a perder.

É importante ressaltar que o dito transtorno da imagem corporal não é causa de um distúrbio alimentar que responderia a uma terapêutica de ortopedia do imaginário corporal, mas — segundo Nieves Soria — a consequência "da aspiração anoréxica de existir como pura imagem”. A mesma autora ressalta que:

“(...) a anoréxica tenta extrair do corpo o excesso próprio da carne, rechaçando o corpo em sua dimensão real, ali onde podemos colocá-lo como substância gozante (...). A contrapartida dessa ambição anoréxica é o retorno do excesso rechaçado através da deformação da imagem especular, essa insistência em se ver gorda (...)." (SORIA, 2001, p.38-39)

Poderíamos dizer que a anoréxica busca desconhecer o enlaçamento entre os registros lacanianos do Imaginário — que diz respeito à imagem corporal — e do Real - que concerne ao corpo em sua dimensão de gozo pulsional. No entanto, a forma localizada de retorno daquilo que foi recusado - a cena frente ao espelho, ponto privilegiado de irrupção da angústia — não aponta para uma estrutura psicótica (SORIA, 2001, p.39). Ou seja, desconhecer o enlaçamento dos registros, no sentido de responder ou consentir com o gozo que daí advém, não implica que eles estejam desenlaçados, como seria o caso na psicose, quando não seria possível distinguir o gozo fálico do gozo feminino. No enlaçamento entre Imaginário e Real, situa-se o gozo Outro, que, como todo gozo, refere-se ao real da pulsão e Outro, porque suplementar ao gozo fálico. Este último, por sua vez, seria regulado pelo significante fálico e situado no enodamento entre Real e Simbólico. 
Nesse sentido, entende-se a indicação freudiana segundo a qual a anorexia nas jovens envolveria uma aversão à sexualidade, explicitaríamos, feminina. Se a posição feminina no jogo dos semblantes corresponde à mascarada, com a “intervenção de um parecer que substitui o ter” (LACAN, 1958b/1998, p.701), cumpre discernir na anorexia uma posição peculiar.

O termo 'mascarada', que Lacan retoma das considerações da psicanalista Joan Rivière (1929/1994), diz respeito aos semblantes de que pode valer-se uma mulher. Enquanto esta psicanalista deixa em suspenso a questão da identidade entre mascarada e feminilidade, Lacan (1958b/1998) assevera que, ao ser o falo, a mulher repudia uma parte de sua feminilidade, especialmente seus atributos na mascarada. Numa leitura retroativa, podemos vislumbrar nessa observação o quanto o falo não chega a recobrir a sexualidade feminina. Mas, enquanto na mascarada, admitida a falta do falo, trata-se de parecer encarná-lo sob a forma do objeto do desejo, na anorexia, o desconhecimento do enodamento entre o imaginário do corpo e o real da pulsão conduz a um recurso à imagem como representante da feminilidade. Caberia sugerir, ainda seguindo as formulações de Nieves Soria, que a anorexia nervosa seria "uma modalidade pela qual a histérica buscaria se nomear como mulher através da imagem do seu corpo, procurando esgotar na imagem a pergunta sobre a feminilidade” (SORIA, 2001, p.42).

Neste sentido, retomando a questão sobre a relação da anorexia com as estruturas clínicas freudianas, aqui mencionada, propomos, neste artigo, considerar a anorexia mental como uma modalidade da histeria seguindo, inclusive, a tradição iniciada com Lasègue, que definiu de forma mais sistematizada o quadro patológico em seu artigo: "Sobre a anorexia histérica” (LASÈGUE, 1873). Não ignoramos que o sintoma anoréxico possa estar presente em outras estruturas clínicas, como na anorexia melancólica, mas nesse caso não se falaria de anorexia mental, reservando-se o termo para a histeria.

Cabe acrescentar, ainda, quanto aos registros Real, Simbólico e Imaginário, que a indicação de Soria sobre o sintoma anoréxico, "nomear-se como mulher através da imagem do corpo”, remete ao registro do Imaginário, que é o terreno próprio da inibição segundo Lacan (1974-1975, lição de 13/05/75). Não por acaso, observamos que as pacientes anoréxicas apresentam uma inibição da função sexual — lembremos que para Freud a inibição atinge uma função - inibição esta que se expressa na amenorreia e no apagamento dos caracteres sexuais secundários (SORIA, 2001, p.42), além da falta de apetite. Isso significa uma prevalência da inibição em detrimento do sintoma e da angústia, se considerarmos a tríade freudiana retomada por Lacan, que ainda estabelece, além da nominação do imaginário pela inibição, as nominações do simbólico pelo sintoma, de um lado, e do real pela angústia, de outro (LACAN, 1974-75, lição de 13/05/1975). 
Nessa mesma direção, é importante indicar que os sofisticados sistemas de cálculos alimentares a que as anoréxicas se submetem, dão testemunho de uma tentativa imaginária de contabilizar, de fazer contorno ao infinito do gozo feminino que o significante fálico poderia talvez circunscrever. "É um sistema de contas e de cálculos, mas os ganhos e as perdas são aí reais" (CACCIALI, 2005b).

Resumindo então o que foi apresentado até aqui: a anorexia "seria uma tentativa de estabelecer uma simetria entre os dois modos de subjetivação do desejo (homem e mulher)", por meio do estabelecimento de uma exceção que permitiria a universalidade do conjunto das mulheres. O desejo em causa nesse empreendimento seria um “desejo paritário” que, sob “o efeito do Outro social democrático e científico” de nossos dias, "buscaria anular a função do não-todo que especifica não somente o lado mulher, mas que é o suporte do sujeito e do qual deriva o psicanalista" (CACCIALI, 2005b).

O sintoma anoréxico é, portanto, abordado pela via da incidência do Outro social contemporâneo sobre os sujeitos do inconsciente. O pressuposto é de que o aumento na frequência dos casos de anorexia nervosa, em nossos dias, corresponderia a um determinado efeito totalitário do discurso científico ou do discurso capitalista (RECALCATI, 2001, p.31).

Sabemos, porém, através de testemunhos históricos, que já existiam anoréxicas em tempos muito anteriores à emergência do discurso científico ou do discurso capitalista. Poderíamos falar então de um "sintoma contemporâneo"? Qual a diferença entre a "anorexia santa” ou medieval e a "anorexia profana” ou moderna (BIDAUD, 1998, p.117)? Passemos agora a examinar a questão da contemporaneidade do sintoma anoréxico.

\section{UM SINTOMA CONTEMPORÂNEO?}

Diversos trabalhos teóricos têm se dedicado a abordar a anorexia mental sob uma perspectiva histórica. Algumas pesquisas situam casos em que o sintoma anoréxico aparece descrito já nos séculos VII a IX, enquanto outras apontam os signos da doença a partir da Idade Média (MICHELI-RECHTMAN, 2003, p.139-140). Os trabalhos dos historiadores Rudolph Bell e Caroline Bynum são referência para o estudo desse tema, especialmente L'anorexie sainte. Jeûne et mysticisme du Moyen Âge à nos jours (BELL, 1994) e Jeûnes et festins sacrés. Les femmes et la nourriture dans la spiritualité médiévale (BYNUM, 1994).

O pressuposto que justifica o interesse desses estudos históricos para os psicanalistas atuais é o de uma analogia entre o que Bell denominou "anorexia santa” e a anorexia contemporânea. Tal é o caminho seguido no campo psicanalítico, por exemplo, por Éric Bidaud: “achamos legítimo aproximar a anorexia mental das condutas religiosas de privação alimentar, não sob o ângulo simples das 
analogias extrínsecas, mas para destacar um movimento comum, uma trajetória saída de uma mesma origem" (BIDAUD, 1998, p.118).

Este último autor procede a uma cuidadosa investigação sobre Catarina de Siena, religiosa medieval que viveu no século XIII, e cuja conduta de privação alimentar arrastou-se por cerca de vinte anos até sua morte por inanição (BIDAUD, 1998, p.120-130). A hipótese subjacente é a de uma aproximação do gozo anoréxico com o gozo místico — gozo místico este que foi abordado por Lacan em sua teoria sobre as fórmulas da sexuação, tendo sido situado do lado-mulher dos seres falantes (LACAN, 1972-1973/1985, p.102).

A tese principal de Bidaud é de que a anoréxica moderna partilha com a anoréxica santa ou medieval o estatuto do objeto alimento como - ao mesmo tempo - mácula e objeto de tentação, no contexto de um Outro materno tentador e que busca estabelecer uma aliança de domínio especular mãe-filha (BIDAUD, 1998, p.129-130). Sendo assim, a relação de Catarina de Siena com sua mãe é tema privilegiado de estudo para o autor.

Contudo, as consequências desse percurso de analogia histórica desembocam numa não-diferenciação estrutural que leva Bidaud a propor que a anorexia seria uma “entidade”, uma "problemática autônoma”, “depois de ter sido um sintoma”. A formulação de Valabrega de que "ela se situa no cruzamento de quatro ordens psicopatológicas: a ordem neurótica, a ordem psicótica, a ordem psicossomática e, enfim, a ordem perversa”, "devendo ser assinalada como estrutura em equilíbrio ou encruzilhada” (BIDAUD, 1998, p.24), dá a justa medida da imprecisão teórica que resulta desse empreendimento.

Micheli-Rechtman, por outro lado, assinala os problemas metodológicos que resultam dessa perspectiva de continuidade histórica entre a anorexia moderna, e a santa ou medieval: "parece muito difícil aplicar a posteriori o diagnóstico de anorexia nervosa apoiando-se essencialmente em elementos biográficos, a partir de fontes históricas cuja confiabilidade foi por vezes colocada em questão, e, sobretudo, em um contexto histórico medieval, onde não existe a noção de patologia psiquiátrica” (MICHELI-RECHTMAN, 2003, p.140).

A abordagem de continuidade histórica tem o mérito de destacar na conduta anoréxica o caráter de reação por parte de algumas mulheres, em diferentes épocas, às estruturas patriarcais opressivas. No caso das santas medievais, tratava-se da reação à falta de reconhecimento, por parte da hierarquia católica, da possibilidade de as mulheres nas ordens religiosas realizarem milagres. Os limites dessa visada sociológico-feminista para a psicanálise são bastante evidentes.

A alternativa seria então situar a anorexia em uma descontinuidade histórica: 
"uma história descontínua da anorexia destaca fundamentalmente a ideia de que não se pode fazer coincidir os signos da anorexia com aquilo que entendemos atualmente por este sintoma, em uma época histórica em que a psiquiatria como disciplina clínica não estava fundada.” (MICHELI-RECHTMAN, 2003, p.141)

No entanto, evitando a possível armadilha do dualismo continuidade-descontinuidade histórica, Micheli-Rechtman propõe que a psicanálise freudiana e lacaniana poderia contribuir para destacar um elemento psíquico estrutural presente na anorexia nervosa, independente da época. Ela se refere, aí, ao fantasma da histérica postulado por Lacan, em que a histérica se identifica ao objeto do fantasma do Outro, ao objeto a do Outro: a/- $\varphi<>$ A. (LACAN, 19601961/1992, p.244).

Segundo essa autora, o objeto ao qual a anoréxica-histérica se identifica é o objeto- nada do Outro. Sabemos que em diferentes momentos de seu ensino, Lacan postulou entre quatro e seis objetos a: o seio, as fezes, o olhar, a voz, o nada e o falo imaginário.

Contudo, a pergunta que cabe formular nesse momento é: será que identificarse ao objeto-nada e "comer nada" - enunciado de Lacan sobre a anorexia, já mencionado aqui — são da mesma ordem?

Quanto à contemporaneidade do sintoma anoréxico, a mesma autora sugere que "se a anorexia é um sintoma de nossa época é porque a anoréxica fecha o circuito da necessidade (...) ela quer "nada”, em um universo onde todo mundo quer "tudo". E ainda:

“este sintoma é contemporâneo na medida que ele vem indicar como o feminino pode libertar-se das obrigações sociais pela colocação em cena de seu próprio corpo. Se a forma ou a expressão desta encenação é estreitamente dependente das normas do momento, a aposta (...) persiste fora dos quadros históricos e sociais, e vem revelar-se na estrutura do fantasma e do desejo." (MICHELI-RECHTMAN, 2003, p.142-144)

Em contrapartida, é importante notar que esta autora parece substituir a antinomia entre perspectiva continuísta e descontinuísta da história pela oposição entre história e estrutura. A estrutura subjetiva da histeria não é trans-histórica, pois depende da emergência do discurso do psicanalista, sem o qual não se poderia delimitar o discurso da histérica com base no que Freud isolou como neurose histérica. O discurso do analista também depende de condições históricas, como o advento da ciência moderna e o capitalismo.

Temos, portanto, até aqui, duas vias de pesquisa que salientam o que haveria de contemporâneo na anorexia mental, procurando oferecer elaborações teóricas 
sobre a razão de uma maior frequência desse sintoma na clínica psicanalítica atual. Vale lembrar, no entanto, que essa suposta maior prevalência é dificilmente aferível pelo psicanalista, uma vez que esta verificação dependeria de estudos estatísticos comparativos que estão fora do alcance do campo da psicanálise. Por outro lado, não contestamos o valor de verdade do testemunho de alguns analistas contemporâneos, segundo os quais um maior número de sujeitos apresentaria o sintoma anoréxico na atualidade.

Uma primeira via de pesquisa corresponde aos estudos de Recalcati e Cacciali, já mencionados, que ligam o sintoma anoréxico a efeitos do desejo do Outro social, mediados pelos discursos científico e capitalista vigentes em nossa época. O “desejo paritário” em causa nesse sintoma — visando estabelecer uma simetria entre os sexos — seria uma consequência do efeito totalitário desses discursos, e resultaria na busca de anulação do "não-todo" (CACCIALI, 2005b). Além disso, Cacciali também propõe uma abordagem do sintoma anoréxico contemporâneo em sua relação com a noção de dom para Lacan:

“em que essa clínica da anorexia nervosa poderia nos dar indicações sobre a atualidade clínica e social do dom? Em uma sociedade em que o princípio regulador das relações sociais é essencialmente econômico, a anorexia pode aparecer como o sintoma de nossa sociedade utilitarista, no sentido de um protesto, de uma resistência a uma sociedade de consumo desenfreada, em particular oral." (CACCIALI, 2005a)

A segunda via de pesquisa sobre a contemporaneidade do sintoma anoréxico não se coloca necessariamente em oposição à primeira, antes referida. Ela considera a anorexia mental sob a perspectiva das novas configurações do sintoma histérico, pressupondo a estrutura do fantasma histérico e a identificação ao objeto-nada do Outro (MICHELI-RECHTMAN, 2003, p.142-144).

Configuração do sintoma histérico, sintoma de uma sociedade utilitarista e de consumo desenfreado, cabe apenas — nos limites deste artigo — indicar algumas alternativas de pesquisa sobre a atualidade da anorexia mental.

A seguir passaremos a abordar, utilizando um fragmento clínico, as particularidades da direção do tratamento. Procuraremos articular, de um lado, o manejo da angústia; de outro, a lógica da formação do sintoma, no que diz respeito à feminilidade e à sexuação — pontos estes já desenvolvidos em outra seção deste trabalho.

\section{"ALIMENTAR-SE DE LUZ": ALGUMAS CONSIDERAÇÕES SOBRE}

\section{A ANGÚSTIA E A DIREÇÃO DO TRATAMENTO}

Renata, adolescente de 13 anos, foi internada após perder quase 50\% de seu peso corporal, como consequência de uma dieta alimentar iniciada vários meses 
antes. No momento em que se iniciou o atendimento psicanalítico, não andava, nem falava com a analista ou com qualquer outro membro da equipe hospitalar. A mãe da paciente, assim como todos os profissionais da equipe que a atendiam, angustiava-se mais e mais frente à falta de resposta às intervenções terapêuticas oferecidas. Chegou-se ao ponto de sugerir que Renata seria “catatônica” e precisaria de uma terapia eletroconvulsiva (ECT).

Carole D.-La Sagna propõe que a anorexia mental é "uma clínica da ausência de angústia” (D.-LA SAGNA, 2007, p.204): a jovem anoréxica não está absolutamente angustiada com sua situação, mesmo com a perspectiva do risco de morte implicado por seu sintoma, ao passo que aqueles que a circundam — familiares, equipe de saúde, etc. — mostram-se extremamente angustiados (D.-LA SAGNA, 2007, p.204-205). Vale evocar o apagamento da angústia na conversão histérica freudiana clássica - bela indiferença ou recalque bem sucedido, como diz Freud (FREUD, 1926[1925]/1986, p.106-107) — comparável à ausência deste afeto na resposta anoréxica.

A direção do tratamento psicanalítico consiste, portanto, em fazer com que a jovem anoréxica perca "o apoio que ela toma sobre a angústia do outro"; e "uma vez que o sujeito é separado da angústia do meio familiar, pode-se ter a chance de que ele reencontre uma relação própria à angústia” (D.-LA SAGNA, 2007, p.207).

Ainda segundo a mesma autora, não se trata de estabelecer com a paciente "uma queda de braço em torno do tema da alimentação", já que o trabalho na análise, “passa-se sobre o terreno da angústia”. É muito "mais interessante e proveitoso colocar o problema sobre o terreno da angústia do que sobre o da alimentação, onde nos oporíamos à força de uma pulsão. Ninguém pode se opor à força de uma pulsão” (D.-LA SAGNA, 2007, p.209).

Em determinado momento da internação de Renata, após várias semanas de silêncio e recusa alimentar, a analista dirigiu-se à paciente dizendo que ela já estava sendo alimentada com um cateter, medicada com antidepressivos, que os médicos, a nutricionista, a fisioterapeuta estavam fazendo o que podiam para ajudá-la. A psicanalista acrescentou ainda que tinha firme disposição de ouvi-la e também de ajudá-la. Mas havia uma parte que cabia a ela, e que, se ela não quisesse, nada disso adiantaria.

O efeito dessa intervenção foi que, dois dias depois, Renata começou a escrever e estabelecer um diálogo com a analista por meio da escrita; no dia seguinte, passou a falar. No decorrer de seu tratamento, foram emergindo significantes como "dependência” e "nervosismo". Algum tempo após sair da enfermaria, surgiu em uma sessão analítica a seguinte formulação: "tenho raiva de depender da comida para sobreviver. Uma mulher foi entrevistada num programa de televisão, ela dizia que não comia nada havia vários anos, só bebia água, e que 
se alimentava de luz. Eu queria ser assim. Será que isso é possível, alimentar-se de luz? Bom, eu acho que ela estava mentindo”.

Haveria algumas dimensões a serem discutidas a partir desse relato clínico. A "raiva de depender da comida para sobreviver" poderia ser relacionada, por exemplo, à dialética da demanda e do desejo enunciada por Lacan, em que se recusa o alimento para fazer valer um desejo, desejo de comer NADA (cf. p.4).

A “dependência” de que Renata tem raiva é a dependência estrutural a que todo sujeito da linguagem está submetido desde o seu nascimento, dependência ao Outro materno, ao Outro da linguagem. Para a anoréxica, o Outro materno é o Outro alimentar.

No entanto, pretendemos privilegiar nesta breve discussão clínica, por um lado, a relação do sujeito com a angústia, relação modificada graças à intervenção do analista; por outro, a contribuição desse fragmento clínico para o entendimento da lógica da formação do sintoma anoréxico.

Quanto ao manejo clínico da angústia, a partir do momento em que o sujeito pode se apropriar de sua angústia ("nervosismo”), a relação à palavra pode ser reinstaurada e, em lugar de existir apenas como corpo-objeto que suscita a angústia do Outro, uma interrogação sobre o desejo do Outro pode se esboçar: “ela dizia que se alimentava de luz. Será que isso é possível?”. A via encontra-se, aí, aberta para que entre em cena o sujeito do desejo.

Da tentativa anoréxica de estabelecer um universal das mulheres, fazendo existir uma que o contradiga (CACCIALI, 2005b; cf. também p.9), Renata passa a questionar a possibilidade de existir uma mulher que se alimente apenas de luz. Ela aponta para a inexistência de uma exceção ao conjunto das mulheres castradas, exceção que ela procurava fazer existir com seu sintoma: $A$ mulher que se alimenta de luz, e que permitiria postular um universal feminino. Na medida que o sujeito faz vacilar essa construção sintomática — "será que isso é possível? Bom, eu acho que ela estava mentindo" - a quase-certeza anoréxica começa a perder sua força. Só aí, então, o caminho para a feminilidade, para tornar-se mulher, pode afinal ser percorrido.

Recebido em 26/3/2009. Aprovado em 7/8/2009. 


\section{REFERÊNCIAS}

BELL, R. (1994). L'anorexie sainte. Jeûne et mysticisme du Moyen Âge à nos jours. Paris: PUF.

BYNUM, C. (1994). Jeûnes et festins sacrés. Les femmes et la nourriture dans la spiritualité mediévale. Paris: Cerf.

BIDAUD, E. (1998) Anorexia mental, ascese, mística: uma abordagem psicanalítica. Rio de Janeiro: Companhia de Freud.

CACCIALI, J-L. (2005a) L'anorexique est-elle anti-utilitariste?. Journées de Paris, Sur le Don. 22 et 23 janvier. Disponível em: www.ecole-freud/ lacan.com/grenoble/index.php?option=com_authorpages\&task

$=$ showauthorcontent\&id $=104 \&$ itemid $=28$

(2005b) “Désir d’aujourd'hui". Jounées de Milan, 17,18 septembre. Disponível em: www.ecole-freud/lacan.com/grenoble/ index.php?option=com_authorpages\&task=showauthorcontent\&id $=104$ \&itemid $=28$

D.-LA SAGNA (2007) C. L’anorexie des jeunes filles. La Cause Freudienne, 65, p.203-211. Paris.

ELMER, D. (1993) De um x que não pode construir-se. Revista Letra Freudiana, 14, p.35-39. Rio de Janeiro: Espaço e Tempo.

FREUD, S. (1986) Obras completas Sigmund Freud, Buenos Aires: Amorrortu. (1895) “Manuscrito G. Melancolia”, v.I. p.239-246.

(1916) "Algunos tipos de carácter dilucidados por el trabajo psicoanalítico (I. Las “excepciones”)”, v.XIV, p.319-322.

(1918 [1914]). “De la historia de una neurosis infantil”, v.XVII. p.1112.

(1926[1925]) “Inhibición, sintoma y angustia”, v.XX. p.71-164.

(1931) “33a conferencia: La feminidad”, v.XXII. p.104-125.

KESTEMBERG, E. e J., DECOBERT, S. (1972) La faim et le corps. Paris: PUF.

LACAN, J. (1956-1957/1995). O Seminário, livro 4: A relação de objeto. Rio de Janeiro: Jorge Zahar Editor.

. (1958a/1998). “A direção do tratamento e os princípios de seu poder”. In Escritos. Rio de Janeiro: Jorge Zahar Editor.

. (1958b/1998). "A significação do falo”. In Escritos. Rio de Janeiro: Jorge Zahar Editor.

(1957-1958/1998). "De uma questão preliminar a todo tratamento possível da psicose”. In Escritos. Rio de Janeiro: Jorge Zahar Editor.

(1960-1961). O seminário, livro 8: a transferência. Rio de Janeiro, Jorge Zahar Editor.

(1962-1963/2005). O seminário, livro 10: a angústia. Rio de Janeiro: Jorge Zahar Editor.

. (1972-1973/1985). O Seminário, livro 20: mais, ainda. Rio de Janeiro: Jorge Zahar Editor.

(1974-1975). Seminário XXII. RSI. Inédito.

LASÈGUE, C. (1873/1971). “De l'anorexie hystérique”. Écrits psychiatriques. Toulouse: Privat, p.135-150. 
MICHELI-RECHTMAN, V. (2003) L’anorexie, un symptôme contemporain?. La Clinique Lacanienne, 6, p.139-144. Paris: Érès.

RECALCATI, M. (2001) Os dois nada da anorexia. Correio: Revista da Escola Brasileira de Psicanálise, 32. p.26-36. São Paulo.

RIVIÈRE, J. (1929/1994) "La féminité em tant que mascarade", in HAMON, Marie-Christine (Org). Féminité et mascarade. Paris: Seuil, p.197-213.

SILVA, A. N. \& BASTOS, A. (2006) Anorexia: uma pseudo-separação frente a impasses na alienação e na separação. Psicologia Clínica,18, p.97-107. Rio de Janeiro, Departamento de Psicologia, PUC-Rio.

SORIA, N. (2001) O corpo na anorexia: da imagem ao semblante. Correio: Revista da Escola Brasileira de Psicanálise, 35, p.38-42.

Simone Pencak

sipencak@uol.com.br

Angélica Bastos

abastosg@terra.com.br 